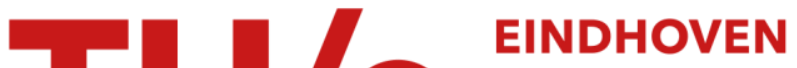 \\ UNIVERSITY OF \\ TECHNOLOGY
}

\section{Matching intelligent systems with business process reengineering}

Citation for published version (APA):

Hart, 't, M. W. (1996). Matching intelligent systems with business process reengineering. International Journal of Intelligent Systems in Accounting, Finance and Management, 5(1), 41-53.

Document status and date:

Published: 01/01/1996

\section{Document Version:}

Publisher's PDF, also known as Version of Record (includes final page, issue and volume numbers)

\section{Please check the document version of this publication:}

- A submitted manuscript is the version of the article upon submission and before peer-review. There can be important differences between the submitted version and the official published version of record. People interested in the research are advised to contact the author for the final version of the publication, or visit the $\mathrm{DOI}$ to the publisher's website.

- The final author version and the galley proof are versions of the publication after peer review.

- The final published version features the final layout of the paper including the volume, issue and page numbers.

Link to publication

\section{General rights}

Copyright and moral rights for the publications made accessible in the public portal are retained by the authors and/or other copyright owners and it is a condition of accessing publications that users recognise and abide by the legal requirements associated with these rights.

- Users may download and print one copy of any publication from the public portal for the purpose of private study or research.

- You may not further distribute the material or use it for any profit-making activity or commercial gain

- You may freely distribute the URL identifying the publication in the public portal.

If the publication is distributed under the terms of Article 25fa of the Dutch Copyright Act, indicated by the "Taverne" license above, please follow below link for the End User Agreement:

www.tue.nl/taverne

Take down policy

If you believe that this document breaches copyright please contact us at:

openaccess@tue.nl

providing details and we will investigate your claim. 


\title{
Matching Intelligent Systems with Business Process Reengineering
}

\author{
Marcel W. 't Hart \\ Eindhoven University of Technology, The Netherlands
}

ABSTRACT According to Venkatraman (1991) five degrees of IT-induced business reconfiguration can be distinguished: (1) localized exploitation of IT, (2) intemal integration, (3) business process redesign, (4) business network redesign, and (5) business scope redefinition. On each of these levels, different types of intelligent systems are applicable. On the level of localized exploitation of IT, the added value of standalone intelligent systems is limited. At the second level (i.e. the internal integration level), intelligent systems may play an important role, especially when they are integrated within information retrieval and messaging systems. On the last three levels, intelligent systems enable new business process solutions by means of 'knowledge reallocation'. Knowieag' reallocation is the process of separation of knowledge from its original resources by transporting it towards earlier stages of the business process. By packaging the knowledge in intelligent systems, the reallocated knowledge becomes usable in the earliest stages of the business process for non-specialized workers. Performance improvements caused by these systems are illustrated by examples in financial services organizations.

\section{INTRODUCTION}

Intelligent systems have a 'solution enabling effect on Business Process Re-engineering. Business process solutions that were formerly infeasible for economic reasons are now attainable by capturing scarce human knowledge via inteliigent systems. However, business processes can be re-engineered on different levels. On each of these levels, other solutions and other types of intelligent systems are needed. In this paper the relationship between five different IT-induced business reconfiguration levels and different intelligent systems is described. This paper gives the reader more insight into the different IT-induced reconfiguration levels distinguished by Venkatraman (1991), along with different types of intelligent systems and the relationships between them. For each of the different Business Process Re-engineering types, examples of inteiligent systems in financial services organizations are descrioed.

\section{BUSINESS PROCESS RE-ENGINEERING: DEFINITION OF THE CONSTRUCT}

There is little agreement in literature of what Business Process Re-engineering (BPR) exactly is, or should be (Renkema and Dolan, 1995). Davenport and Short (1990) have called BPR 'Process Innovation' which is defined as 'the analysis and design of workflows and processes within and between organizations'. According to Hammer (1990), BPR has a radical character: Reengineering is the fundamental analysis and radical redesign of business processes to arhieve dramatic improvements in critical measures of performance.' Alter (1990) defines BPR as a radical redesign effort as well, but introduces information technology as an 
additional element: 'Business Re-engineering (also known as work re-engineering or business process redesign) is a methodological process that uses information technology to radically overhaul business processes and thereby attain major business goals.' Venkatraman (1991) proposes a more differentiated approach towards the radical element in BPR: 'BPR involves the reconfiguration of the business using IT as a central lever. Instead of treating the existing business process as a constraint in the design of an IT infrastructure the business process itself is redesigned to maximally exploit the available IT capabilities.'

This paper follows the definition of BPR proposed by Venkatraman, because of the nuance in specifying the radical element of BPR. The degree to which BPR is radical can be determined according to levels of business reconfiguration distinguished by Venkatraman. Because of the fact that not all BPR projects are equally radical, in our opinion the central element in BPR is not the radical character of the redesign effort. The central element is the maximal exploitation of IT capabilities in the redesigned business processes. The maximal exploitation of IT capabilities may force radical changes of business processes.

Although IT is a central lever for BPR, the success of a BPR project depends upon many other factors, such as management commitment, expertise of the project members, etc. An analysis and further description of these critical success factors is beyond the scope of this paper.

\section{IT-induced Business Transformation}

The role of IT in BPR can be described on different levels of business transformation (levels of change). In Table 1 , the leveis of ITinduced business transformation are paraphrased from Venkatraman (1991, pp. 127-128). In Figure 1 the levels of change are illustrated.

Venkatraman states that the first two business reconfiguration levels are viewed as evolutionary, requiring relatively incremental changes in the existing organizational processes. Although these levels are considered evolutionary, Brown (1994) states that the changes required of an organization moving from level one to level two are profound. The other three levels are conceptualized as revolutionary, requiring fundamental changes in the nature of business processes. The central premise at the revolutionary levels is that $\mathrm{IT}$ is a lever for designing business processes and that it should not be simply overlaid on the existing organizational context. The potential benefits are predicted to increase with each succeeding level of IT usage (Keen, 1988), although there is considerable risk associated with moving to the revolutionary levels without mastering internal integration (Yapp and Macdonald, 1992).

\section{Requirements for intelligent Systems on Each Level}

Intelligent systems applied on a particular reconfiguration level need to have certain level specific characteristics. These characteristics can be considered as requirements that should be fulfilled by intelligent systems applied for the purpose of attaining a certain reconfiguration level.

- Localized exploitation: On this reconfiguration level, intelligent systems need to make sure that individual human task performance is improved. This implies that a requirement of intelligent systems is that they be able to simulate or even outperform the human worker on certain aspects of the task. Therefore, knowledge necessary for task execution demands to be formalized to a very large extent.

- Internal integration: On this reconfiguration level, the coherence within the business process should be improved by intelligent systems. A high degree of coherence is reached when: (1) all actors within the business process use the same procedures and working methods, and (2) all necessary knowledge and information is accessible for all relevant actors. Therefore, intelligent systems should be able to: (1) provide structure in procedures and working methods, and (2) detect and control the necessary communication of knowledge and information.

By providing structure in procedures and working methods intelligent systems establish uniformity within business processes. In the case of non-prespecified (i.e. non-deterministic) 
Table 1 The five levels of change

\section{(1) Localized exploitation}

Level one is localized exploitation, concerned with the exploitation of IT within business functions, or different stages of the business process. This localized deployment of IT applications is often concerned with the improvement of efficiency of operations. Applications serve some localized goals without necessarily influencing related areas of operation.

\section{(2) Internal integration}

Level two is internal integration, which is a logical extension of the firs! in the sense that IT capabilities are exploited in all the possible activities within the business process. The deployment of a common IT platform serves to integrate the organization's business processes, potentially enhancing efficiency arid effectiveness. (3) Business process redesign

Level three is business process redesign, involving the reconiiguration of the business process using IT as a central lever. Instead of treating the existing processes as a constraint in the design of an optimum IT infrastructure, the business process itself is redesigned tc maximally exploit the available IT capabilities. This reflects conscious efforts to create an alignment between the IT infrastructure and the business processes.

\section{(4) Business network redesign}

Level four is business network redesign, concened with the reconfiguration of the scope and tasks of the business network involved in the creation and deilvery of products and services. This inciudes the business tasks within and outside the formal boundaries of a focal organization and the consequent redesign of this 'virtual business network' through IT capabilities.

\section{(5) Business scope redefinition}

Level five is business scope redefinition, concerned with the raison d'etre of a corporation, pertaining to the possibilities of enlarging the business mission and scope (through reated products and services) as well as shifting the business scope (through the substitution of traditional capabilities with iT-eriabled skills).

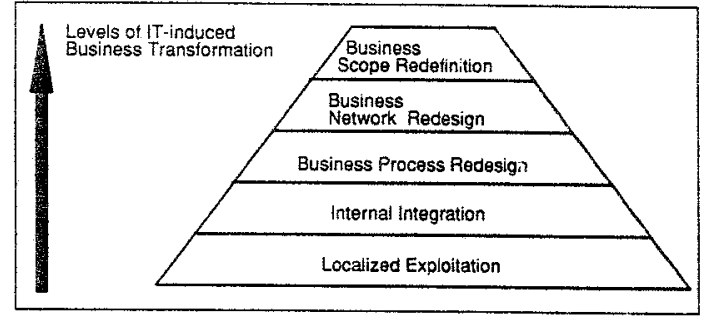

Figure 1 The five levels of IT-induced business reconfiguration

business processes, uniformity in procedures and working methods can only be realized by means of the 'intelligent' capabilities of intelligent systems. In non-prespecified business processes, the routing and tasks are determined during the processing of individual cases. Characteristics of individual cases determine what (sequences of) tasks need to be fulfilled. To be able to control both product and process quality (e.g. average lead time), the routings and individual working methods need to be dynamically and conditonally constructed by intelligent systems.
To provide all workers with all recessary knowledge and information, (intelligent) systems need to overcome time and place constraints. Messaging and database technologies enable communication between actors without the condition of all actors cornmunicating on the same time and place. However, these technologies cannot guarantee that all necessary knowledge and information is communicated whenever this is needed. Intelligent systems should therefore be applied to detect and control the necessary communication of knowledge and information.

- Business process redesign: In knowledge-intensive organizations, efficiency goals are often conflicting with effectiveness goals such as: quality of service, lead times, waiting times, etc. From an efficiency viewpoint, it is essential to employ scarce experts only if necessary. As a result, many business processes contain filtering processes and waiting queues between the market (clients) and the experts' tasks. To fulfill effectiveness goals, however, it is important to reduce the amount of filters and buffers between experts and clients. Business process redesign efforts should focus on obtaining both efficiency 
and effectiveness goals in processes in which experts and clients interact. By simulating human intelligence in an intelligent system, efficient as well as effective utilization of knowledge should be achieved in these processes.

- Business network redesign: On this reconfiguration level, intelligent systems need to enable the attainment of a new improved balance between efficiency and effectiveness goals as well. However, the reconfiguration scope is expanded outside the organizational boundaries. Business processes of more than one organization are affected by these reconfiguration efforts. After reconfiguration, the resulting business process is often referred to as being controlled by a new virtual enterprise. In this virtual enterprise, original organizations are cooperating intensively. This cooperation aspect creates an additional requirement for intelligent systems. The intelligent systems contain core competence knowledge of participating organizations. Although this knowledge beccmes accessible for other organizations within the virtual enterprise, every organization should remain in control of their 'own' knowledge. Therefore, the separation of 'the usage of knowiedge' from 'the control of knowledge' is an important requirement on this reconfiguration level.

- Business scope redefinition: Enlarging as well as shifting the business mission and scope through related products and services implies the redefinition of the product/ market combinations of an organization. After redefinition of the business scope, the reconfiguration effort is quite similar to business process network or business process redesign. Each new, or changed product/ market combination is enabled because of the IT possibilities for creating new or reengineered business processes. Thus, business scope redefinition in itself introduces no additional or other requirements for intelligent systems compared to the two other revolutionary reconfiguration levels.

\section{INTELLIGENT SYSTEMS}

Before different types of intelligent systems can be related to the described types of IT- induced business reconfiguration, the term 'intelligent systems' should be defined. Traditionally, a machine is considered 'intelligent' when it passes the Turing Test (Turing, 1950). In this line of thought, several thinkers have claimed that none of the techniques currently being explored will ever achieve true, humanlevel intelligence (e.g. Dreyfus and Dreyfus, 1986).

Contrasting the traditional, more philosoph:cal perception of intelligent systems, this paper defines intelligent systems from a functional point of view. Information systems that are capable of inferring new intormation are considered 'intelligent systems'. New information is information that is not retrieved from memory or put in manually, but is inferred based upon a certain degree of domain knowledge combined with existing information (i.e. existing in the IT system). The inference of new information based upon domain knowledge and existing information is sometimes called 'conditional intelligence'. In other words, conditional intelligence is the ability to operate in a decision-making capacity in changing conditions.

\section{Difierent Types of Inieiligent Systems}

To be able to define what kind of irtelligent systems are applicable on each business reconfiguration level, different types of intelligent systems need to be distinguished. Types of intelligent systems can be distinguished based upon the following two dimensions:

(1) The amount of intelligence (information inference) of an intelligent system.

(2) The combination of the information inference function with other main IT functions.

\section{The Amount of Intelligence of an Intelligent System}

The primary function responsible for inferring 'new information' in an intelligent system is called 'information inference'. This function is not present and applied to the same extent in every IT application. The extent to which an IT application contains information inference can be determined based on the following two perspectives: 
(1) Information inference on a certain task description level. Tasks can be decomposed into sub-tasks on a more detailed level. This process of decomposition is recursive (i.e. it can be repeated on every task description level). Thus, tasks can be described on different hierarchical levels. Every intelligent information system supports tasks on a certain task description level. When a high-level decision task is supported with information inference the information system is often considered more intelligent than an information system supporting a low-level decision task.

(2) The task distribution between human and computer. Often, certain parts of a task are fulfilled by the intelligent information system, while other parts have to be executed by the user of the system. This means certain sub-tasks of a higher level task are fulfilled by the information system, while others are not. Given a certain task description level, the sub-tasks of a higherlevel task are distributed between the (intelligent) information system and the human agent.

This task distribution perspective can be worked out in more detail. Card et al. (3986) described ten possible types of task-distribution models between a human and $a r_{1}$ intelligent computer system. The differences between these ten types of models are too detailed for the scope of this paper. The amount of information inference (the intelligence of an information system), given task description level, can be specified in four different types. These types can be considered classes of Card's types.

\section{Enable}

The 'enabling' type of information inference implies that the user does the entire task while there is no support from information-inferring functionality at all. The information system only offers certain functions that can be selected by the user of the system. The choice of using one function over another has to be determined by the user without any support from the information system. Therefore enabling functionality will never be labelled 'intelligent'. In practice, this kind of functionality is quite common in information systems containing many manipulation functions, such as 'cut and paste', 'copy', or 'select and execute' functions.

\section{Support}

Support functionality means the user is supported in the selection of the next step in the process (the next sub-task). Support functionality is the first type of information inference that can ice considered to be somewhat intelligen:. This type of information inference takes the user 'by the hand' through the work process. This type of functionality is often considered intelligent when there are many alternative paths of getting through the process, and the information system chooses one or more of these paths based upon contextual information.

Support furictionality is often used in applications to structure the way of working within semi-structured (non-deterministic) human tasks and business processes. It can be applied both on the (more detailed) individual task level as well as on the (more aggregate) business process or workflow level.

\section{Advice}

The capability of advising a user to complete the task is a primary characteristic of advice functionality. Advice functionality is offered to the user of an information systern when the user receives content-based advice. The advice functionality differs from the support functionality described in the previous paragraph. Within the support functionality, the user is only facilitated in the selection of what to do next. The advice functionality not only infers what to do next but also gives the user advice concerning the output of the chosen task. Classical knowledge-based systems, such as those for medical diagnosis, credit approval, hardware configuration, etc., contain information inference functionality on the advice level.

\section{Automate}

Information inference on the 'automated' level means a task is completely executed by an information system. With advice functionality the user is often shown more than one option, although one (or more) of these options is actually advised. The user is often provided the possibility to choose a non- 
advised option. With automated functionality the user is only able to approve or disapprove the inferred conclusion of the information system.

\section{The Combination of the Information Inference Function with Other Main IT Functions}

In (intelligent) information systems, information inference is often used in combination with other main IT functionalities. The main functionalities of information systems can be determined based upon the metaphors of computer usage. In its short history the computer has been used as a: (1) calculator, (2) memory machine, (3) communications machine, and (4) reasoning machine. Both the calculator and reasoning machine use information inference as the most important functionality type, although the calculator is primarily based upon quantitative information inference while the reasoning machine is based upon qualitative reasoning.

The computer as a memory or communications machine is based upon the 'communication' functionality of computers. Singh Kahai and Cooper (1990) distinguish between timedelayed communication and real-time communication. With delayed communication, the message is not directly sent to its ultimate receivers but is stored with the idea that it will be retrieved by the receivers when needed. With real-time communication no storage of this type is intended and the message is sent directly to its receivers. This does not mean that there could be no storage of messages. However, with real-time communication the storage of messages is not the intention of the senders. The computer, as a memory machine, refers to functionality for facilitating timedelayed communication (for instance, by using database technology). Real-time communication functionality has led to the computer as a communications machine metaphor.

Based upon the difference between timedelayed and real-time communication, this paper distinguishes three main functionalities of (intelligent) systems:

- 'Information storage and retrieval' functionality: which enables time-delayed communication
- 'Messaging' functionality: which enables real-time communication

- 'Information inference' functionality: which enables the inference of new information that is not retrieved from storage, or received from other actors, or put in manually.

Messaging and information retrieval functionality can both be combined with a certain amount of information inference. This creates 'intelligent messaging systems' and 'intelligent information retrieval systems'. The characteristics of these systems will be described in the following sections.

\section{The Type of Intelligent System for Each Reconfiguration Level}

Different business reconfiguration leveis require different intelligent systems. In the remainder of this paper the relationships between the levels and the systems are described. In Figure 2 the relationships between the different business process reconfiguration levels and the different types of intelligent information systems are shown. For every reconfiguration level both the requirements for intelligent systems and the applicable intelligent systems types (that fulfill these requirements) are presented. As described earlier in this paper, there are no additional requirements for intelligent systems on the business scope redefinition level. On this level, the requirements of the business process redesign level (and possibly those of the business network redesign level as well) are applicable.

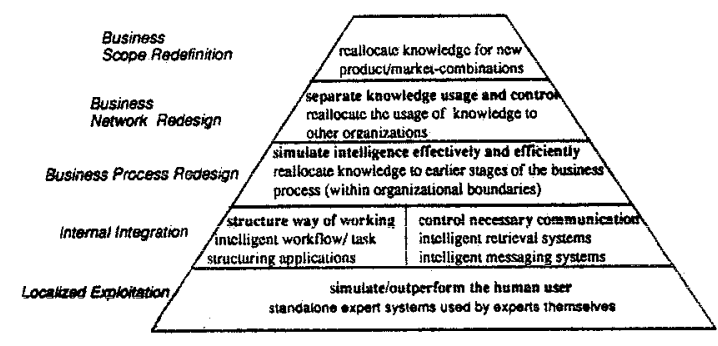

Figure 2 The reconfiguration levels related to types of intelligent systems 
For every reconfiguration level other than business scope redefinition every requirement from lower reconfiguration levels are valid on higher levels as well. Therefore, intelligent systems applied on the business process redesign level not only need to simulate human intelligence effectively and efficiently. Intelligent systems applied on this level must (1) structure the way work has to be done, (2) detect and control the necessary communication of knowledge and information, and (3) outperform or at least match the knowledge level of the ultimate end-user.

The intelligent systems that enable each business reconfiguration level are shown in Figure 2. Of course, these types of intelligent systems are applicable in projects that aim for higher business reconfiguration levels as well. However, applied on a higher level they need the enabling capacities of the higher-level intelligent system types. Only these higherlevel intelligent systems are capable of fulfilling the higher-level requirements.

\section{Intelligent Systems Related to Evolutionary Business Reconfiguration Levels}

In this section the first two evolutionary business reconfiguration levels are described according to the intelligent systems that support these evolutionary change processes. The last three reconfiguration levels can be considered Business Process Re-engineering types that require revolutionary usage of intelligent systems. Examples of these systems are described in the following sections.

\section{Level 1: Localized Exploitation}

On the localized exploitation level, IT is used to optimize or support local processes. This kind of business reconfiguration was common before the introduction of Business Process Re-engineering. The intelligent systems built during this period were often experimental applications. Examples of this business reconfiguration level are the expert systems that have been built for supporting experts themselves. These expert systems are standalone applications that are not integrated within the business processes and information infrastructure. Usually, there is no combination of information inference with other main IT func- tionalities such as localized messaging or information retrieval (i.e. exchanging and accessing information within the localized environment).

Especially for medical domains, standalone diagnosis systems have been built. These diagnosis systems are meant to support the (medical) expert's judgements. Although these systems proved the applicability and technological feasibility of Artificial Intelligence outside the laboratory, the added value of this kind of system is limited. The quality of the judgements of the expert can only be improved by these sytems when they perform better than the human expert. Under some circumstances this kind of system will prevent the human expert from ignoring important facts or incorrect reasoning. In addition to quality improvements, productivity growth can be reached by intelligent systems. However, to reach productivity gains, intelligent systems at least need to match the knowledge level of the human expert. The costs of building a system that matches or even outperforms the knowledge level of the human expert are often larger than the benefits.

\section{Level 2: Internal Integration}

Currently, intelligent information systems play an important role in the internal integration of business processes. The IT-induced internal integration of organizations is established in two dimensions. The first dimension in which organizations become better integrated is called 'process integration'. In this context, process integration means that collaboration and coordination of the chains of a business process is improved. The second dimension in which integration is established is 'functional integration'. Functional integration means that confreres working in different business processes are enabled to share their knowledge.

Process integration is realized by intelligent messaging systems such as intelligent workflow management applications. Functional integration is supported by intelligent informationretrieval systems. Intelligent informationretrieval systems such as hypertext and conceptbased retrieval systems enable knowledge sharing between confreres working in different business processes.

Each of the mentioned intelligent systems 
that can be used for internal integration is described in more detail in the next section.

\section{Workflow Applications}

Workflow (management) applications facilitate the coordination of (electronic) documents within a workflow. Electronic documents can be sent and received by different agents within the business process (within the workflow). The paperless office is the ideal situation sought by every workflow application. These kinds of systems are now being increasingly implemented in financial services and insurance organizations. These organizations utilize many documents, such as request forms for auto collision insurance. These documents are more easy to handle (i.e. to store, to distribute, to copy, to retrieve) when they are transformed into an electronic format (an electronic document). Workflow applications enable electronic documents to be sent to the different agents within the business process, and to keep track of documents within the business process. However, before sending a document to another agent the other agent must first be selected on the basis of competence and credentials. Thus, before sending the document, a 'routing decision' has to be taken. Regarding the amount of information inference, document routing is often supported on an enabling level in non-intelligent workflow systems. However, the added value of workflow applications can be increased enormously when document routing is supported on an advice or automated level. Especially within non-deterministic business processes this kind of system can be called an 'intelligent workflow system'. Using an electronic format, the intelligent workflow system automatically recognizes document characteristics and deduces the destination of the document. When documents have a fixed format, high information inference levels are attainable. Reasoning about the routing of freeformat documents (such as letters) is more difficult, since automatic interpretation of natural language has still not proved to be attainable in these contexts.

\section{Intelligent Messaging}

Both 'intelligent e-mail' and 'information filtering' are application domains of intelligent messaging systems. Using intelligent e-mail applications, messages are labelled with respect to the stages of a communication process. Winograd's 'Coordinator' is probably the bestknown example of this kind of system (Winograd and Flores, 1986). By labelling every message according to its stage in a communication process, the following message in a communication process can be deduced. This implies that the communication process is supported by information inference on the described 'support' level.

Messaging systems that support information filtering and message routing provide human agents with the opportunity to define their personalized information filter and routing preferences (e.g. SIFT developed at Bellcore's Applied Research). In the personalized filters, priority rules can be formulated in order to receive only those messages that are considered relevant. These priority rules may contain domain knowledge combined with personalized priority rules. These information filters are especially useful in filtering conferencing and bulletin-board messages.

\section{Intelligent Information Reírieval}

There are at least two types of information retrieval systems that are often called intelligent: hypertext systems and concept-based retrieval systems. Hypertext systems are different from other conventional retrieval systems in the sense that those other systems are goaloriented. In these conventional systems the user has to define the problem as precisely as possible (depending on the matching techniques that are applied). However, users do not always know exactly what they are looking for. In the literature this state of the user being unfocused is called an 'anomalous state of knowledge' (e.g. Brooks et al., 1986). In hypertext systems it is possible to browse and navigate through chunks of knowledge which are ordered in a networked structure of 'knots'. These networked knots are interlinked through 'hyperlinks' which have the same effect as cross-references in an encyclopedia. When one wants to know more about a certain subject, one can select that particular subject and travel through the hyperlink to the knot containing more information on it. Information inference 
functionality can be added to a hypertext in order to detect relevant parts of hyperspace automatically.

Concept-based retrieval systems depend on a deep knowledge of the vocabulary of the document set, the semantics of the language being used, and the subject matter at hand (Khoshafian et al., 1992). The words in a document are weighted according to their relevance to each other across the whole document space, without any bearing on whether or not they appear together in any given individual document. These systems depend on sets of rules, equivalence and synonym lists.

Both hypertext and concept-based retrieval systems can be used to establish internal integration. After successfully completing integration, the revolutionary Business Process Reengineering levels (shown in Figure 1) come within reach. BPR is the subject of the remainder of this paper.

\section{INTERMEZZO: KNOWLEDGE REALLOCATION}

To be able to describe the relationship between the previous three levels of IT-induced business configuration and different intelligent systems the concept of 'knowledge reallocation' needs to be introduced. Intelligent systems applied on these levels need to enable the attainment of possibly conflicting business goals by employing the revolutionary allocation of knowledge. Often conflicting business goals, such as a reduction of lead times combined with improvement in efficiency and quality, have to be sought. A reduction in lead times can be achieved by removing transportation processes and waiting queues. However, these transportation processes and waiting queues result in the efficient utilization of relatively scarce and expensive knowledge workers. By using knowledge reallocation, this conflict between business goals can be eliminated and formerly impossible goals and business processes become attainable ('t Hart et al., 1993).

\section{What is Knowledge Reallocation?}

Knowledge technology has enabled one to consider knowledge at a logical level, which means independent of physical resources, such as personnel, manuals, procedures and information systems. A prerequisite for knowledge reallocation is a separation of knowledge from its original resources. When the original resource of knowledge is human, knowledge elicitation is necessary for the separation process. After separation, the knowledge can be transported to, and made available in, other stages (sequences of actions) of the business process. This process of separation of knowledge from its resources and the transportation to and application of the knowledge in other stages of the business process is called knowledge reallocation. By reallocating knowledge to earlier stages of the business process, employees working in these stages have more knowledge at their disposal. This available knowledge makes these stages more autonomous and capable of operating more effectively and efficiently. However, to be able to work with this new knowledge, the knowledge has to be 'packaged' in such a manner that non-specialists are able to use it. By packaging the knowledge in intelligent systems the reallocated knowledge becomes usable for the less educated or experienced knowledge workers in the earliest stages of business processes. Because these early stages in business processes (sometimes called 'front-office processes') are in direct contact with clients, the clients can be serviced more effectively and efficiently.

\section{Knowledge Reallocation Related to Revolutionary Business Reconfiguration Levels}

In this section for each of the revolutionary business reconfiguration levels the impact of knowledge reallocation is described as are examples of the reconfiguration types with corresponding intelligent systems that are implemented in financial services organizations. These examples are described in detail in 't Hart et al. (1993), explaining the impact of knowledge reallocation in process design. For the scope of this paper, these examples are shown for the purpose of recognizing and 
understanding the potential impact of intelligent systems on the revolutionary business process re-engineering levels. In these examples, all knowledge elicitation necessary for knowledge reallocation has been completed by using the KADS model-based knowledgeelicitation approach which is integrated within the knowledge-based systems design methodology 'Structured Knowledge Engineering TM. (sce, for example, Breuker and Wieleriga, 1991; Breuker et al., 1987).

\section{Level 3: Business Process Redesign}

On the business process redesign level, intelligent systems need to simulate human intelligence effectively and efficiently. This implies the reallocation of knowledge to earlier stages in the business process of the focal organization. The following example is concerned with a redesigned business process in an insurance company. Within the focal business process claims for damages are processed. Performance improvement has been realized by an intelligent system reallocating knowledge for quality inspections.

Claims for damages are often physically documented on forms. These documents are not always filled in consistently, compietely, accurately or truthfully by clienis or $b y$ (telephone) operators. Orten, after documents have been erroneously completed, they are sen to back-office knowledge workers, who are not able to process them. After inspection by the knowledge workers these erroneously completed forms have to be returned to the data entry process, and the activities must be repeated. This kind of disturbance has a sharp negative impact on the logistical performance of the business process. in cases where the logistical performance requirements are not met due to this phenomenon, quality improvements are needed from the data entry process.

These quality improvements require a redesigned business process. The business process is redesigned by removing quality inspection knowledge from the knowledge workers and transferring it to the employees responsibie for the data entry process. To be able to perform these quality inspections, the front-office employees need to have the knowledge necessary for the different quality inspections at their disposal. Checks for consistency and veracity can be knowledge-intensive activities. By reallocating this knowledge from the knowledge workers to the data entry process, logistical performance requirements can be met. The reallocated knowledge is implemented in the form of an intelligent system to make the reallocated knowledge accessible for the frontoffice employees. The irtelligent system operates in conjunction with an electronic entry form (for telephone operators) and with document imaging and optical character recognition software (for forms filled in by clients). These forms can be sent electronically to the backoffice knowledge workers by means of a workflow application. Before sending the forms, the intelligent system checks the form for inconsistencies and other errors. In case of an error an aiternative course of action is proposed by the system. The workload within the data entry process and the assessment process is reduced due to the removal of unnecessary repetitions, thus improving throughput, customer service and efficiency of the redesigned business process.

\section{Level 4: Business network redesign}

In the previous (level 3) business process reengineering took place within a single organization. On level 4 of BPR, the use of IT for redesigning the collaboration between participants in a business network is described. Electronic Data Interchange (EDI) is a popular technique in business network redesign that alters the governance structure between organizations because of the increased interdependency between stages (e.g. Creemers, 1993). However, the specific impact $\mathrm{EDI}$ on business network redesign is beyond the scope of this paper. Moreover, the application of EDI in the following example is not a necessary condition for business network design. The redesigned business network could rely equally on traditional communication media. In the example it will be shown that the application of knowledge reallocation is essential for the redesigned business network.

In a number of insurance companies in the Netherlands, intelligent systems have led to redesigned business networks. The most striking example of this kind of system are the insurance acceptance systems which insurance companies have implemented in agents' offices. 
In the past, one went to an independent insurance agent for auto collision insurance and then the person (or the agent) filled in a request form, which was sent to the central office of the selected insurance company. After having filled in the form the person waited for an answer from the insurance company. Currently, it is possible to obtain the answer immediately, due to the fact that a number of insurance companies have installed intelligent systems that reside in agents' offices. The knowledge needed to make the decision to accept a new client, which was formerly centralized at the insurance company's main office, is now reallocated to the geographically distributed agents. This reallocation of knowledge, from the central office to the individual agents near the clients, has reduced lead times (timeto-market) of the insurance company. Time-tomarket is reduced due to the removal of intermediary processes, i.e. the transportation and waiting queues between the insurance company and the agents have largely disappeared. The quality and efficiency of the assessments have improved considerably as well, for knowledge-based systems have proved to work more consistently than human beings. Consequently, this consistency facilitates uniformity of working methods. In addition, the quality of work of the knowledge workers at the central assessment department has also been improved. Ninety percent of all request forms (the standard cases) are presently handled by the knowledgebased system. This implies that there is relatively more time available to handle the more interesting or novel $10 \%$ of the remaining cases. This remaining 10\% is handled 'preknowledge reallocation', although this is now done more effectively and efficiently due to the reduced workload.

An issue of strategic importance in this case is the distinction between usage and control of the knowledge. The reallocated knowledge is used by other organizations (in this case the independent insurance agents). However, the knowledge cannot be altered by the agents because the control of the knowledge remains the responsibility of the insurance company. The usage and control of knowledge are separated by using a run and an edit version of the intelligent system. Agents have access only to the run version. The insurance company creates and distributes new run versions by using the edit version of the intelligent system. In this manner, the additional requirement on this business reconfiguration level is fulfilled.

\section{Level 5: Business Scope Redefinition}

This last level is concerned with the redefinition of the business scope. Venkatraman (1991) distinguishes between (1) business scope enlargement and (2) business scope shifts. Although no additional requirements for intelligent systems applied on this reconfiguration level are stated throughout this paper, the following example will illustrate the enabiing capacities of intelligent systems for achieving business scope enlargement.

Banks are moving from a product-oriented approach towards a client-oriented one. In the product-oriented approach, clients are transferred to a number of different product specialists (e.g. fiscal, mortgage, investment and security specialists). In the client-oriented approach, clients are offered balanced combinations of financial products which are customized to their unique situations and needs.

Of course, it is not economically feasible to have a number of different product specialists available 'behind the counter' in order to establish the client-oriented approach. In fact one 'general specialist' behind the counter is only economically feasible for servicing affluent clients. Currently, inteiligent systems make the client-oriented approach attainable for the middle range of the market. An important part of the knowledge of the different specialists is integrated in a knowledge-based system. The integrated knowledge is reallocated to the counters of the distributed offices.

Clients with average incomes can now be served by employees using client-oriented intelligent systems that integrate the knowledge of a number of different product specialists. Customer service is increased considerably because many clients can be serviced at the counter by non-specialized employees. Only complex cases are handed over to specialists who, in turn, have more time available to handle them. This example shows that intelligent systems enable organizations to approach their markets with a different strategy, and thus accomplish more challenging goals. 


\section{CONCLUSION}

Different types of intelligent systems have been described according to the five different ITinduced business reconfiguration levels distinguished by Venkatraman. The types of intelligent systems that enable each business reconfiguration level have been distinguished. These types of intelligent systems are applicable in projects that also aim at higher business reconfiguration levels. However, applied on a higher level, the enabling capacities of the higher-level intelligent system types are needed. Only these intelligent systems are capable of fulfilling the higher-level requirements.

On the first level, i.e. the localized exploitation' of IT, the intelligent system needs to outperform the human expert (the user) on certain aspects in order to have added value. On the second level (internal integration) intelligent systems play an important role, especially when they are integrated within information retrieval and messaging systems. Applied for reaching this level, intelligent systems must be able to provide consistency and structure in the way work is done, as well as to make sure that all relevant knowledge and information is accessible for all actors when needed.

The last three reconfiguration levels are revolutionary levels of change. The potential added value of intelligent systems is enormous on these levels. However, mastering the internal integration level is a prerequisite for moving to the revolutionary levels. On these revolutionary levels, intelligent systems enable new business process solutions by using 'knowledge reallocation'. Knowledge reallocation is the process of separation of knowledge from its original resources and the transportation to and application of the knowledge in earlier stages of the business process.

On the third level, knowledge is reallocated to earlier stages of the business process within the organizational boundaries. By simulating human intelligence in intelligent systems (containing the reallocated knowledge), efficient as well as effective utilization of knowledge in these earlier stages is achieved. On the fourth level, i.e. 'business network redesign', there is an additional requirement for intelligent systems. The reconfiguration scope is expanded outside the organizational boundaries, which implies that the reallocated knowledge is made accessible for other organizations within the same virtual enterprise. On this level, the usage of knowledge and the control of knowledge need to be explicitly separated in order to protect this valuable asset. On the last reconfiguration level, i.e. 'business scope redefinition', no additional requirements for intelligent systems are stated.

\section{REFERENCES}

Alter, A., The Corporate Make-over, CIO, December 1990, pp. 32-42.

Breuker. J.A. et al., Model-Driven Knowledge Acquisition: Interpretation Models, Deliverable task A1, Esprit Project 1098, Amsterdam, 1987

Breuker, J.A. and Wielenga, B., KADS: A Modelling Approach to Knowledge Engineering, University of Amsterdam, Amsterdam, 1991.

Brooks, H.M., Daniels, P.J. and Belkin, N.J., 'Research on information interaction and intelligent information provision mechanisms', Journal of Information Science, 12, 1986, pp. 37-44.

Brown, A., 'Getting value from an integrated IS strategy', European Journal on Information Systems, 3, No. 2, 1994, pp. 155-165.

Card, S.K., Moran, T.P. and Newell, A.L., 'The model human processor', in Boff, K.R. et al., (eds), Handbook of Perception and Human Performance, Vol. 2, John Wiley, New York, 1986, pp. 45:1-45:35.

Creemers, M.R., Transaction Engineering: Process Design and Information Technology beyond Interchangeability, University of Amsterdam, Amsterdam, 1993.

Davenport, T.E. and Short, J.E. "The new industrial engineering: information technology and business process redesign', Sloan Management Review, Summer 1990, pp. 11-27.

Dreyfus, H.L. and Dreyfus, S.E., Mind over Machine, The Free Press, New York, 1986.

Hammer, M., 'Reengineering work: don't automate, obliterate', Harvard Business Review, July-August 1990, pp. 103-112.

Hart, M.W. 't, Fokkink, J.G. and Veldhoen, B.J.H., 'The impact of knowledge reallocation in process design', Proceedings Conference Kennistechnologie '93, 27-28 October 1993, Amsterdam, pp. 429-437.

Keen, P., Competing in Time, Ballinger, New York, 1988.

Khoshafian, S., Baker, A.B., Abnous, R. and Shepherd, K., Intelligent Offices: object oriented multimedia information management in client/server architectures, John Wiley, New York, 1992.

Renkema, T.J.W. and Dolan, T., 'Investment-based analysis of IT-enabled Business Process Reengineering: a case study within engineering data 
management', Proceedings IFIP 5.7 Conference, April 1995.

Singh Kahai, S. and Cooper, R., The design of computer-based support for task communication within organizations', Proceedings of the 11th International Conference on Information Systems, 1990, Copenhagen, pp. 25-35.

Turing, A.M., 'Computing machinery and intelligence', Mind 59, 236, 1950, pp. 433-460.

Venkatraman, N., 'TT-induced busines reconfiguration', in Scott Morton, M. (ed.), The Corporation of the 1990s Information Technology and Organizational Transformation, Oxford University Press, New York, 1991.

Winograd, T. and Flores, F., Understanding Computers and Cognition: a New Foundation for Design, Ablex Publishing Corporation, Norwood, NJ, 1986.

Yapp, C. and Macdonald, $K$., 'IT strategies: issues and prescriptions', in Brown, A. (ed.), Creating a Business-based IT Strategy, Chapman and Hall, London, 1992. 